\title{
The Impact of Neuromarketing Advertising on Children: Intended and Unintended Effects
}

\author{
Amani Al Abbas ${ }^{1}$, Weifeng Chen ${ }^{1}$, and Maria Saberi² \\ ${ }^{1}$ College of Business, Arts and Social Sciences, Brunel University London, UK \\ ${ }^{2}$ College of Business \& Finance, Ahlia University, Bahrain
}

\section{Abstract}

Purpose: This research is aimed at assessing the impact of neuromarketing advertisements on children. This is carried out by establishing the two types of effects that can occur as a result of neuromarketing advertising: intended and unintended effects.

Design/Methodology/approach: The researcher intends to use a quantitative approach.

Findings/expected outcomes: Findings will shed the light on which factors (intended vs. unintended) have more power on children. Based on that, conclusions, recommendations will be established and raised to concerned parties.

Corresponding Author:

Amani Al Abbas

Amani.alabbas@brunel.ac.uk

Received: 22 July 2019

Accepted: 16 September 2019

Published: 19 September 2019

Publishing services provided by

Knowledge E

(c) Amani Al Abbas et al. This article is distributed under the terms of the

Attribution License, which permits unrestricted use and redistribution provided that the original author and source are credited.

Selection and Peer-review under the responsibility of the PwR Symposium Conference Committee.

\section{G OPEN ACCESS}

Practical implications /social implications: Children are the most impressionable sector of our society. By performing this research, neuromarketing can now have the chance to prove that it can be used for the greater good if in fact proven to have more power as an intended effect advertising tool to aspire change.

Originality/Value: The research present literature review and a conceptual framework to assess those effects on children in the context of neuromarketing. These effects has not been tested in the context of neuromarketing as well as their collective impact on those children.

Keywords: Neuromarketing; Advertising; Intended effects; Unintended Effect; Children

\section{Introduction}

Over the years, marketing has aimed at better anticipation of the effectiveness of advertising campaigns. Morin (2011) states in his article that traditional techniques have failed to predict effectiveness with accuracy since emotions have a strong effect on how consumers process images, and understand and model cognitive reactions to messages.

In addition, the amount of data consumers are subjected to is gigantic, and the brain's ability to perform analysis is finite. Out of an average of 11 million bits of data that consumers are subjected to through their senses per second, only 50 bits of that data are analyzed by the brain, letting the rest go by ignored (Wilson, 2002). This made companies thirsty for the attention of the consumers and lead to the use of neural 
approaches to construct more effective advertisement or even reach consumers at a subconscious level if possible (Fugate, 2007).

Late years have seen a development in the capacities of neuroscientists to consider cortical activities regarding recurrence and revelations. Surely, the late procedures of functional imaging have allowed a profound learning in neuroscience and an exactness of cerebrum zones in charge of a delights and feelings. Be that as it may, most sociologies have yet to perceive neuroimaging as a standard method for examination and marketing research has been far slower to wake up to the benefit from this system (Lee, Broderick, and Chamberlain, 2007). Financial analysts were the first to propose the "neuroeconomics" (Zak, 2004; Kenning and Plassmann, 2005; Rustitchini, 2005). The point was to better comprehend the choice procedure or decision making (Droulers and Roullet, 2006). Late years have seen the advancement of another discipline which can be named as "neuromarketing" or "NM". The objective of this rising discipline is the exchange of knowledge from neurology to explore the buying behavior by applying neuroscientific strategies to marketing important issues (Stoll et al., 2008). Consequently, we can consider that the NM is the place marketing and neuroscience meet.

\subsection{Background of the study}

Much like any new field, NM has its promoters and opponents. The French Parliament has revised its 2004 rules on bioethics. The result, passed in 2011, is a section of the law that simply states: "Brain-imaging methods can be used only for medical or scientific research purposes or in the context of court expertise" (Oullier 2013). The revised law effectively bans the commercial use of neuroimaging in France, although NM companies have only to cross the border to continue their business. Thus, in France, pursuing any commercial research and any act of commercialization by using brain imaging techniques is banned. However, it is still possible to carry out NM research by means of biometric techniques such as eye-tracking and galvanic skin response etc. This revision caused serious debates among neuroscientists and politicians about the exact position of neuroimaging technologies, and it was also stressed that the use of neuroimaging techniques in courts still takes place, despite the fact that there have been several cases of failure in this technology concerning reliability. Technology, NM included, is a twosided coin that can hold benefits as well as potential harm specially when dealing with a vulnerable segment such as children. In this research, the researcher attempt to assess the impact of exposure to NM advertisement on children (both intended and unintended 
effects) and to suggest ways to better understand and use such technologies when it comes to children being the most valued aspects of the future.

\section{Literature Review}

Marketing is defined as the process, set of foundations, and procedures for making, conveying, delivering, and trading offerings that is of value for clients, customers, accomplices and society.

Also marketing is the management procedure through which products and services move from being an idea to the end client. It incorporates the mix of four components called the 4 P's of marketing: (1) distinguishing, identifying and development of an item or a product, (2) determination of its cost, (3) determination of a circulation channel to achieve the client's place, and (4) development and implementation of an advertising plan

The marketing mix is a tool utilized in business. The marketing mix, initially coined by Neil Borden, can be profitable while deciding an item or brand's offer, and is regularly connected with the four Ps. The four Ps was proposed by Professor E. Jerome McCarthy in the 1960s (Nelson, 2016)

Advertising being one of the marketing mix is not really a late human attempt; archaeologists have revealed signs promoting property for rent going back to Pompeil and old Rome. Town messengers were another early type of promoting. As an industry, advertising and promoting did not take off until the availability of the different broad communications: printing, radio, and TV. However, worries over promoting focusing on kids went before both radio and TV. The British Parliament passed laws in 1874 planned to shield kids from the endeavors of merchants to incite them to purchase item (Kunkel and Wilcox, 2004)

NM, on the other hand, is according to Morin (2011), a relatively new evolving discipline which combines examined consumer behavior with neuroscience. Originally controversial field, which first appeared in 2002, is now becoming not only credible, but has also been ranked by specialists among advertising and marketing.

The combination of neuro and marketing expresses merge of two branches, namely neuroscience and marketing. Several US companies began to provide research and consulting in the field of NM, which promoted the use of knowledge and technology derived from the field of cognitive neuroscience. Javor et.al (2013) also describe NM as a discipline that is increasingly used in recent years in media as a theme and also add 
that these public discussions are generally directed on potential ethical aspects and point out concerns about negative impact on society, especially on consumer.

Therefore, NM includes the direct application of brain images, scans, or other measurements that detect any brain activity in order to gauge the reaction of consumers to particular products, services, brands, promotions, or other marketing essentials (Plassmann et al., 2012, p19).

One of the most impacting interdisciplinary fields that affects marketing is Neuroeconomy which brings the financial and economical meaning into the neuronal model for basic decision making (Egidi, 2008). Neuroeconomy developed as an autonomous field due to the expanded enthusiasm for exploring how the basic decision making really happens. The increased popularity of which discipline is due to the decreasing costs of neuroimaging, permitting scholars to study the procedures and processes of decision making on a bigger scale, finding the mind responses that decide complex subjective procedures. Scholars now have the potential to connect neuroscience ideas like basic decision making, memory or feelings with marketing ones, for example, targeting, and response to brands or brand loyalty (Perrachione and Perrachione, 2008).

These neural methods are paving the way for marketers to probe the consumers' brains in order to attain important information as to the reasons for the success or failure of a message (Wilson, Gaines and Hill, 2008). In addition, diversity marketing recognizes the influence of cultural backgrounds on the values, tastes, beliefs, and expectations, and on how to interact, ways of entertainment, and lifestyles, and since diversity marketing acknowledges that these differences require customized marketing tools, an argument emerged that stipulates that NM could hypothetically limit diversity. As such, by using NM, advertisers will be able to overcome limitations imposed by marketing on the basis of demographic, psychographic and geographic information and focus on the individual, which lessens marketing diversity efforts (Feit, 2007).

Although the idea of using brain activity measuring instruments to study consumers' reactions initiated a rather significant appeal and interest, people have yet to discover the other side of the coin. There are the potential ethical issues introduced by the use of NM for commercial purposes especially when it comes to the niche vulnerable population. Individuals that would be considered from this population are those (or family members of those) with diseases in the neural system or having disorders of psychological nature, children, and other parties of legally protected groups (Coenen, 2007).

However, Solanis et al. (2013) say in their article that there is rather limited scientific proof that marketers have gained more power through using NM.. First, the complex 
nature of the methods used to investigate brain responses is poorly understood by marketing agencies. Second, there is a huge consensus among the scientists that analyzing the data generated by neuroimaging tools remains in its infancy. Therefore, the commercial leverage attained by marketers using NM is, if any, highly speculative. Adding to that, marketing professionals and researchers have remained hesitant to accept the techniques of neuroscience due to some suggested limitations about the capacity of the data gathered by those techniques to provide helpful results about consumer insights. Some scholars believe that the role of neuroscience and neuroimaging is still too inadequate to replace conventional research techniques when it comes to analyzing and influencing consumer behavior. These scholars believe that it is the mutual use of different methods (both neural and conventional) within consumer research that is vital for an accurate and detailed understanding of the different components of consumer behavior. (Solnais, et al., 2013).

\subsection{Neuromarketing Tools}

There are three well known, non- invasive techniques for mapping the brain: functional magnetic resonance imaging (fMRI), electroencephalography (EEG) and magnetoencephalography (MEG).Because of their safe use from ethics point of view, they are the techni9ques used in the studies that have been published in the previous years. Despite the fact that EEG is a somewhat old innovation, it is still viewed as a decent device to gauge the brainwaves.

EEG has a relatively low cost which in turn made them popular for NM; but these possess a weakness of not providing information on how the selections are triggered. MEG measures provide much better information and insights into the brain, but this comes with a much higher cost than the previously mentioned method. Unlike the previous technologies, fMRI uses a scans to evaluate the variations of the flow of the in blood in the brain. Since it offers deep images of the brain constructions, it is also the most popular technology used in NM studies. Test subjects see the experience as a positive one, viewing the process as a fascinating one (Senior et. al, 2007).

\subsection{Practical Uses of Neuromarketing}

Uses and implications of NM include but not limited to: 


\subsubsection{Testing The Effectiveness Of Advertising}

Traditional measuring of new advertising campaigns usually involves interviews, focus groups, recall and other conventional methods of marketing research. As per the supporters of NM, participants could be wired to imaging tools while watching pictures or video cuts of a new ad.

According to which zones of the brain "light" up, triangulations can be made about the participant's unconscious thought designs. Assuming that the company's goal for the promotion, e.g. trill, passion, vibe, attention, hostility, consideration, and so forth.; can be coordinated to the zone of brain where these ideas are handled. On the off chance that that mind region is unaffected after introduction to the promotional motivator, clearly the ad has failed this vital test. On the other hand, motivators that create a quantifiable change in a predefined zone of the mind induce an effective match albeit genuine buy behavior is still an unanswered inquiry. Generally speaking, NM is seen as an approach to help promoters change their messages; to know whether an advertisement will even escape the beginning entryway (McConnon and Stead, 2007). Ford Motor Company and Pre-Diction; a UK based research firm, have performed limited on car promotional ads.

In addition, the giant British company Unilever and the Brainwave Science people tried one of their TV commercials with utilizing an EEG. The item exhibited and brand message part of the Unilever advertisement evoked much weaker reactions than anticipated. The components that should bring out negative feelings were doing much better yet the overall the commercial did not create the respondent reactions that were expected. Such an analysis endorsed for new advertisement executions ought to help the marketing and advertising group find something new; something significant to add to their imaginative endeavors (Harris, 2006).

\subsubsection{Testing Product Appeal}

Product engineers regularly utilize deliberately created customer preferences to figure out which products are most speaking to their target customers. In such settings, customers are liable to be affected by norms and social factors. Moreover, shoppers make numerous unconscious behaviors that are past conventional strategies that use reflection (Economist, 2004). But with NM legitimate reactions ought to be more achievable (Friedman, 2006). For instance, review inquire about ordinarily reports that ladies 
discover wrestler-turned-actor legend "The Rock" not attractive however records of brain activity demonstrates something else (Singer, 2004).

\subsubsection{Celebrity Endorsements}

Marketers have since quite a while ago trusted that celebrity endorsements lead to more product appeal and more sales. Tiger Woods, Michael Jordan, Katherine ZetaJones, and an extensive rundown of different celebrities have been heavily paid on the grounds that their big name status supposedly helps profits and sales. Be that as it may, as of not long ago, nobody could pinpoint how the sound-related and visual ads using those celebrities help the brand. However, NM provides marketers with an approach to make the last choice of endorser in light of physical proof (Fugate, 2007).

According to Fugate (2007), profoundly well-known and enjoyed big names would be most helpful with items and/or item messages that are prone to be under suspicion. On the other hand, the brain is additionally designed to keep away from danger; an aftereffect of survival inclinations. Once a face gets to be connected with negative or offensive outcomes, the human brain has a tendency to keep away from contact with that picture. This maybe clarifies the breaking of endorsement deals with big, high paid big celebrities.

\subsubsection{Logo or Brand Selection}

Advertisers normally participate in the act of giving human-like identities to their brands or items, e.g. fun, dependable, dedicated. Yoon et al. (2006) speculated those purchasers' decisions about descriptive words used to depict individuals and items would be handled in various areas of the brain. In their trial, fMRI demonstrated that the left sub-par prefrontal cortex was dynamic amid judgments about brands and the average prefrontal cortex was dynamic amid judgments about individuals. While customers may credit human qualities to brands and items, these attributions are not mean the same as they are for individuals. This suggests numerous conversation for the advertisers that create brand identities (Eastman, 2006). 


\subsubsection{Media Selection}

One way to deal with media selection depends on Hansen's (1981) application of the hypothesis of hemispheric lateralization. Analysts expected that nonliteral, all encompassing, and pictorial pictures were put away and handled on the right half of the mind. This would propose lower request, latent, conceivably subliminal and emotional handling of data in the right half of the hemisphere of the mind. The fitting medium for promoting messages of the "right side" sort would be TV messages of brief length, rehashed every now and again since detailed assessment of message content was not present.

The left side was more fitting for higher order subjective cognition, for example, objective (in the financial sense) decision making. "Left side" promotions ought to be print where more genuine data could be given targeted people.

\subsection{Implications of Advertising to Children}

The investigation of advertising effects on children has been based in general on two paradigms: The empowered child and the vulnerable child paradigms. In the first paradigm, being the empowered child paradigm, children are considered as being capable of critically process and evaluate advertisement. On the other hand, the vulnerable child paradigm children assumed to not possess the cognitive skills to shield themselves against advertising messages and it is believed that those kids are more prone to fall for the seductive allure of those marketing attempts.

Research drawn from these two paradigms concentrate on two advertising effects: intended and unintended effects.

\subsubsection{Intended advertising effects:}

The intended effects of advertising which is based on the empowered child paradigm suggests that these effects are anticipated and favored by marketers.

Research has focused on three depended factors: cognitive effects, affective effects and behavioral effects.

Children are considered a big market by promoters according to McNeal (1992). They have significant access of cash to spend on their needs and wants. Second, children are likewise a future market as they progress to being adults. studies has exhibited that kids create brand devotion at an early age, and that good demeanors toward 
brands last well into adulthood (McNeal, 1992). Lastly, kids are an imperative market of influencers. Not just do they provide guidance to every day family buys, for example, snacks, desserts, and breakfast items, as they get more seasoned, they additionally can pester their parents and caretakers into buying them stuff (Gurtter and Furnham, 1998; McNeal, 1992). Since children are perceived as buyers; producers, companies, and advertisers have turned out to be take real interest in this segment (Buijzen, \& Valkenburg, 2002).

There has been many models constructed to study the process by which people go through when assessing advertising to reach a decision. One of these models is AIDA which stands for: A:Attention, I:Interest, D:Desire, A:Action. The AIDA model display expresses that marketers ought to know how to draw the attention of a purchaser to get the client intrigued or interested by showing its favorable circumstances, advantages and components. Interest is trailed by the desire to have the product. It is marketers' obligation to make a yearning in a consumer to purchase a particular item. Every one of the three stages of AIDA will help to motivate the activity towards buying an item (Hanlon, 2013).

Another model with the name DAGMAR has now become more used than the AIDA model due to its comprehensiveness compared with AIDA. DAGMAR stages are more defined and a bit easier to relate to. According to Hanlon (2013), the term DAGMAR stands for Defining Advertising Goals for Measured Advertising Results. DAGMAR model states that an advertisement must carry a potential customer through four steps:

1. Awareness, Which is basically transforming the customer from not being aware of the brand or the product into knowing them.

2. Comprehension, Which refers to transforming the awareness of the products into a better understanding of the brand or the product and their benefits.

3. Conviction, which means that marketers must convince customer by telling them the benefits of the brand or the product.

4. Action, which is not controlled by marketers. If marketers have been able to convince, the customer and have answered them satisfactorily then the action of buying will occur.

The Hierarchy of Effects Model was originated by Robert J Lavidge and Gary A Steiner in 1961. This marketing advertising model expresses that there are six steps from viewing an advertisement to actual product purchase (Figure 1). The job of the marketers is to lead and encourage the customer to go through the six stages and purchase the product. 


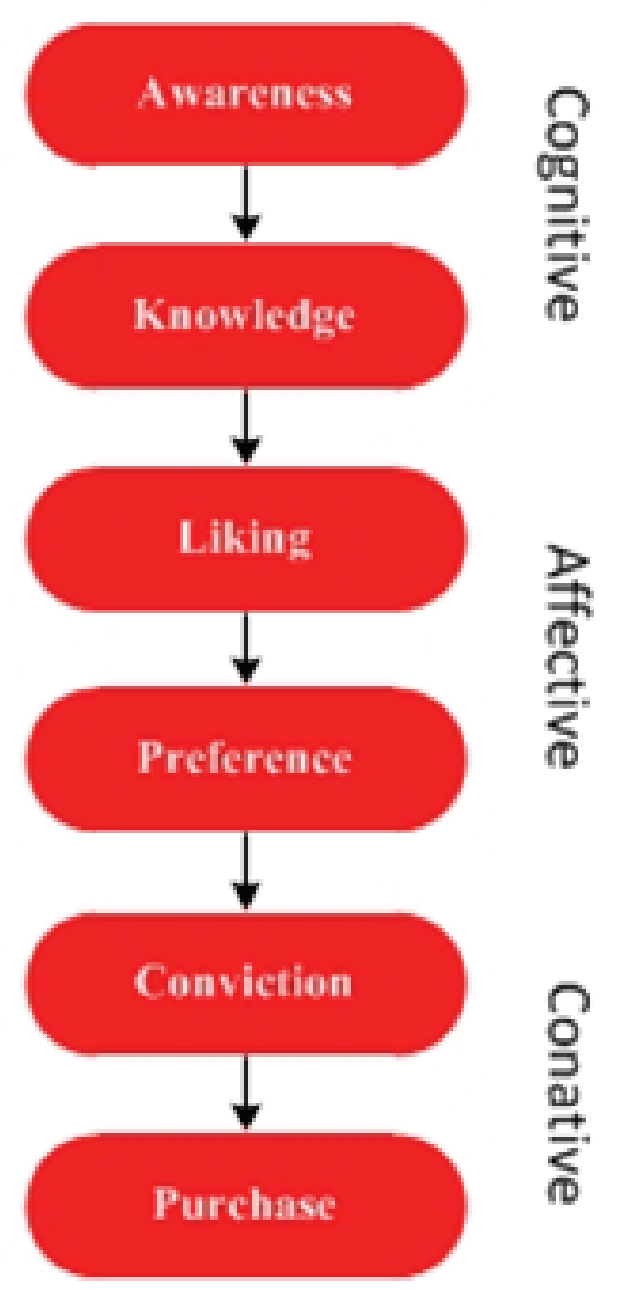

Figure 1: The Hierarchy Of Effects Model. Source: learnmarketing.com.

Looking into these models, they basically fall under three common categories of intended advertising effects as illustrated in table 1.

TABLE 1: Advertising Models Comparison.

Cognitive Effect
Affective Effect
Behavioral Effect

\begin{tabular}{|c|}
\hline AIDA \\
\hline Attention \\
\hline Interest Desire \\
\hline Action \\
\hline
\end{tabular}

Hierarchy of Effects
Awareness Knowledge
Liking Preference
Convection
Purchase

DAGMAR
Awareness Comprehension
Convection
Action

These intended effects are what marketers wan to achieve from the advertising process. However, using NM will amplify these effects and even might override the children's ability to assess the advertising correctly, especially considering that children are under developed when it comes to their cognitive abilities (John, 1999). Leading them to fall under the valuable child paradigm. 


\subsubsection{The Vulnerable Child Paradigm}

Children are considered from the vulnerable population. Targeting children is considered highly unethical to many concerned parties (Buijzen, \& Valkenburg, 2003). Looking into in view of the vulnerable or powerless child paradigm reflects the unintended impacts of advertising, which are the negative impacts or the byproduct of advertising. Looking into the unintended advertising impacts has dominatingly centered around three dependent factors: parent- child conflict, consumerism and disappointment and frustration. The unintended impacts of advertising have gotten most research consideration from many concerned parties and researchers.

Studies have suggested that advertising encourages materialism and consumerism in children (Greenberg \& Brand, 1993; Wulfemeyer and Mueller, 1992). Studies revealed that advertising enhances consumerism because such promotional messages is intended to arouse desires for these products that would not otherwise be noticeable by children. Advertising amplifies the philosophy that possessions are important and that more is more. Also, these ads promote the idea that some desirable qualities such as success, beauty and happiness can be acquired only by obtaining products (Pollay, 1986; Wulfemeyer \& Mueller, 1992).

Advertising causes parent-child conflict This conflict arises when children's purchase requests after ad viewing are denied. These conflicts can be really difficult to handle and some parents can be pestered by their children resulting in the parent caving in and buying the advertised product(Atkin, 1975; Robertson, 1979; Furnham and Gunter, 2008).

Life dissatisfaction. Advertising is viewed to promote an alternative world full of beautiful people, better things and nice products. When children view ads and start comparing their own situation with this fantasized world, the difference between the two worlds can cause disappointments and frustration (Furnham and Gunter, 2008; Richins, 1991; Martin \& Kennedy,1993).

The above mentioned effects can be magnified when working with such accurate, targeted advertising campaigns that utilized NM thus calling for serious research and attention to all parties involved to better regulate this sector. (Bulley, Braimah and Blankson, 2018)

In the course of recent decades, the increase in targeted ads towards children. This led to raising the alarm, especially with the introduction of technologies such as NM.

A group of psychiatrists communicated their worry to the APA (American Psychological Association) in 1999 regarding using psychology to exploit children for commercial 
purposes which is regarded as being highly unethical. By not taking care of the issue, they showed that the APA was violating its own code of conduct. Psychologists likewise get data from the field of neuropsychology to create NM strategies that are intended to help marketers achieve the triune mind (the emotional midbrain and the primitive receptive brain) so as to make it "basically unimaginable for basic thinking and successful decision marking to happen while viewing an advertisement" (Schor, 2004, p. 111). Psychologists were utilizing their knowledge to help organizations advertise and market to children focusing on and encouraging consumerism amongst those children. The information in the course of recent years have appeared, and keep on showing, that excusive consumerism in children, tweens, and adolescents causes damage.

\section{The Theoretical Framework}

In this section, the theoretical framework for the study is discussed. Based on the previous studies on the two child paradigms, a theoretical framework has been suggested to evolve into a conceptual framework that can be tested in the context of NM (figure2). This research novelty lays in the testing of the two paradigms as well as the testing them in a new context (NM context). This reveal the negative and positive impact NM holds on children thus leading policy makers to act accordingly. In addition, this research can lead to utilize the power of technology to better the lives of children by channeling it in the right direction.

\section{Summary}

Many scholars voices some concerns regarding these NM tools as those could lead to a "unitary thought" which damage the functions and values traditionally attributed to an individual children, starting with a children's ability to direct their own path in life and taking responsibility for their actions. Both now under the threat of being altered or manipulated and thus lead to undesired effects that jeopardize those children's overall wellbeing.

Progression from children to adult consumer who has been subjected since infancy by NM techniques forms a potential area for further investigation and research. Children are the most impressionable sector of our society. By performing this research, NM can now have the chance to prove that it can be used for the greater good if in fact proven to have more power as an intended effect advertising tool to aspire change. 


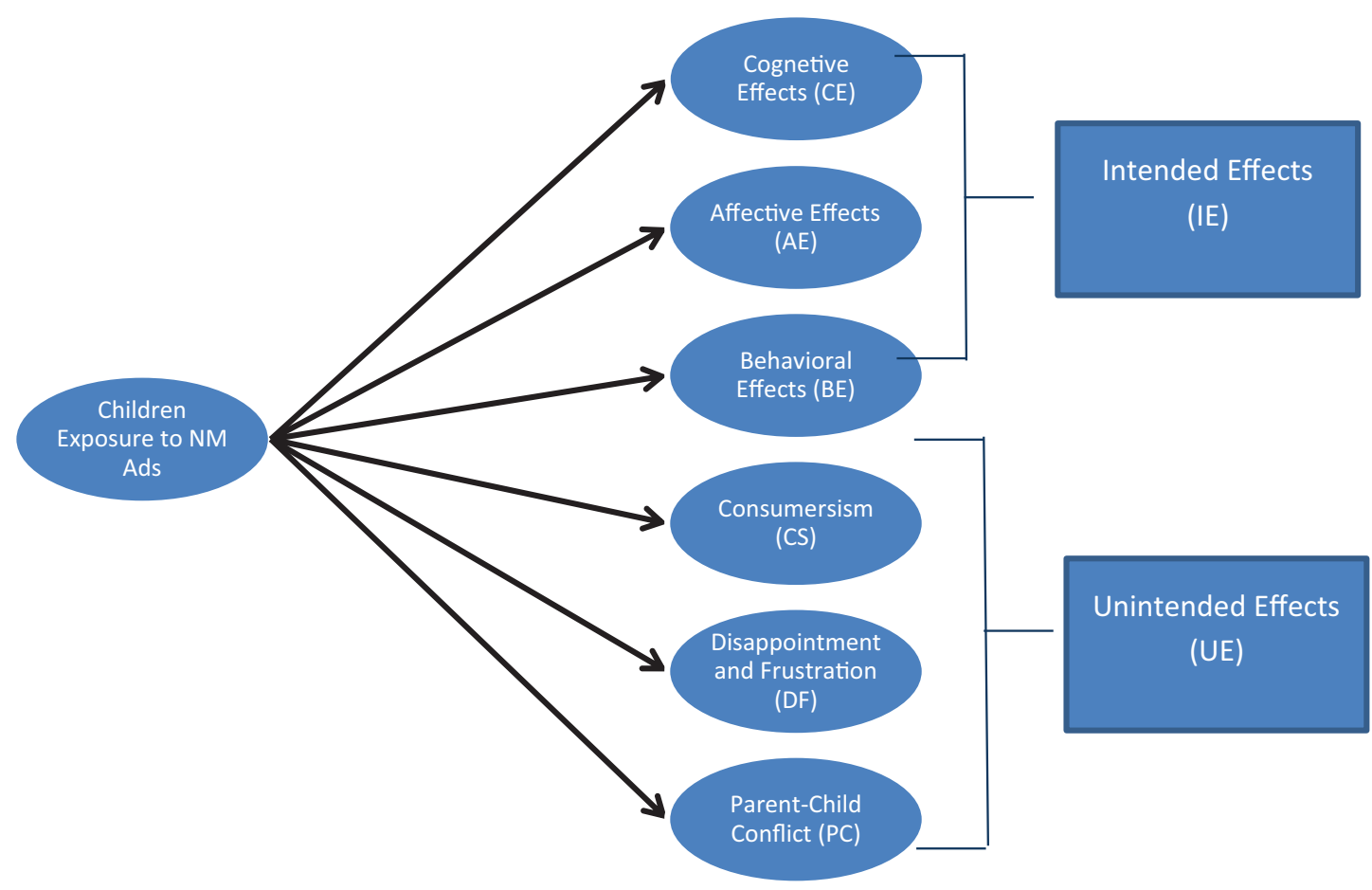

Figure 2: The Theoretical Framework of the Study.

\section{References}

[1] Association, A.P. (2016) Ethics in psychology. Available at: http://www.apa.org/topics/ ethics/ (Accessed: 2 January 2017).

[2] Atkin, C.K., 1978. Observation of parent-child interaction in supermarket decisionmaking. Journal of marketing, 42(4), pp.41-45

[3] Buijzen, M. and Valkenburg, P.M. (2003) 'The unintended effects of television advertising: A parent-child survey', Communication Research, 30(5), pp. 483-503. doi: 10.1177/0093650203256361.

[4] Bulley, C.A., Braimah, M. and Blankson, F.E., 2018. Ethics, Neuromarketing and Marketing Research With Children. International Journal of Customer Relationship Marketing and Management (IJCRMM), 9(2), pp.79-95

[5] Coenen, D. (2006). Future of Footnote Four, The. Ga. L. Rev., 41, p.797.

[6] Droulers O, Roullet B (2006). Neuromarketing: Cadre théorique et perspectives. Paper present end at the XXII ${ }^{\circ}$ Congres of the French Marketing Association, 11-12 may Nantes, France.

[7] Eastman, D. (2006), Neuromarketing: The Application of Cognitive Neuroscience to Marketing Research, Western Kentucky University, Bowling Green, KY

[8] Economist (2004), "Inside of the mind of the consumer", Economist, Vol. 371 No. 8379, p. 12. 
[9] Egidi,G.; Nusbaum, H.C.; Cacioppo, J.T. (2008). Neuroeconomics: Foundational issues and consumer relevance in: Haugtvedt, C., Kardes, F. and Herr. P. (eds.), Handbook of Consumer Psychology, Mahwah, NJ: Erlbaum, pp. 1177-1214

[10] Feit, J. (2007) Neuromarketing and diversity go hand-in-hand. Available at: http://adage.com/article/the-big-tent/neuromarketing-diversity-hand-hand/121687/ (Accessed: 13 November 2016).

[11] Friedman, R.A. (2006), “What's the ultimate? Scan a male brain”, New York Times, Vol. 156 No. 53743 , p. G10

[12] Fugate, D. (2007). Neuromarketing: a layman's look at neuroscience and its potential application to marketing practice. Journal of Consumer Marketing, [online] 24(7), pp.385-394.Available at: http://www.emeraldinsight.com/journals. htm?articleid=1637461 [Accessed 29 Dec. 2013].

[13] Furnham, A. and Gunter, B., 2008. Children as consumers: A psychological analysis of the young people's market. Routledge

[14] Greenberg, B.S. and Brand, J.E., 1993. Television news and advertising in schools: The" Channel One" controversy. Journal of Communication.

[15] Gunter, B., \& Fumham, A. (1998). Children as consumers: A psychological analysis of the young people's market. London, UK: Routledge

[16] Hanlon, A. (2013) The AIDA model - smart insights digital marketing advice. Available at: http://www.smartinsights.com/traffic-building-strategy/offer-and-messagedevelopment/aida-model/ (Accessed: 14 May 2015).

[17] Hansen, F. (1981), "Hemispheral lateralization: implications for understanding consumer behavior", Journal of Consumer Research, Vol. 8, June, p. 23

[18] Harris, R. (2006), "Brain waves", Marketing Magazines, Vol. 111 No. 20, pp. 15-17

[19] Javor, A., Koller, M., Lee, N., Chamberlain, L. and Ransmayr, G. (2013) ‘Neuromarketing and consumer neuroscience: Contributions to neurology', BMC neurology., 13.

[20] John, D.R., 1999. Consumer socialization of children: A retrospective look at twentyfive years of research. Journal of consumer research, 26(3), pp.183-213

[21] Kenning P, Plassmann H (2005) Neuroeconomics: an overview from an economic perspective. Brain Res. Bull., 67: 343-35

[22] Kunkel, D. and Wilcox, B. (2004) Television advertising leads to unhealthy habits in children. Available at: http://www.apa.org/news/press/releases/2004/02/childrenads.aspx (Accessed: 18 January 2016).

[23] Lee, N., Broderick, A.J. and Chamberlain, L. (2007) 'What is "neuromarketing"? A discussion and agenda for future research', International Journal of Psychophysiology, 63(2), pp. 199-204. doi: 10.1016/j.ijpsycho.2006.03.007. 
[24] Martin, M.C. and Kennedy, P.F., 1993. Advertising and social comparison: Consequences for female preadolescents and adolescents. Psychology \& Marketing, 10(6), pp.513-530.

[25] McConnon, A. and Stead, D. (2007), "If i only had a brain scan", Business Week, Vol. 4018 No. 19, 22 January, p. 19

[26] McNeal, J. U. (1992). Kids as customers: A handbook of marketing to children. New

[27] Morin, C. (2011). Neuromarketing: the new science of consumer behavior. Society, 48(2), pp.131-135.

[28] Nelson, B. (2016) 'What comes after those ellipses?', in Available at: http://www. businessdictionary.com/definition/marketing.html (Accessed: 27 May 2016).

[29] Oullier O (2013) Behavioural insights are vital to policy-making. Nature 501: 463-463

[30] Perrachione, T.K. and Perrachione, J.R. (2008) 'Brains and brands: Developing mutually informative research in neuroscience and marketing', Journal of Consumer Behaviour, 7(4-5), pp. 303-318. doi: 10.1002/cb.253.

[31] Pollay, R.W., 1986. The distorted mirror: Reflections on the unintended consequences of advertising. Journal of marketing, 50(2), pp.18-36

[32] Richins, M.L., 1991. Social comparison and the idealized images of advertising. Journal of consumer research, 18(1), pp.71-83

[33] Robertson, T.S., 1979. Parental mediation of television advertising effects. Journal of Communication.

[34] Rustichini A (2005) Neuroeconomics: present and future. Games Econ. Behav., 52 : 201-212

[35] Schor, J. (2004) Born to buy: The commercialized child and the new consumer culture. Available at: https://books.google.com.bh/books?hl=en\&lr=\&id= NRxxuTlyt6AC\&oi=fnd\&pg=PR9\&dq=info:d8wbcjxJVugJ:scholar.google.com\&ots= 71jjfVDS7r\&sig=Y31Km4|3e9ShobKDnQ30Qvp9ilU\&redir_esc=y\#v=onepage\&q\&f= false (Accessed: 27 January 2015).

[36] Singer, E. (2004), “They know what you want”, New Scientist, Vol. 183 No. 2458, pp. 36-7.

[37] Solnais, C., Andreu-Perez, J., S’anchez-Fern', ez, J. and Andr'eu-Abela, J. (2013). The contribution of neuroscience to consumer research: A conceptual framework and empirical review. Journal of Economic Psychology, 36, pp.68-81.

[38] Stoll M, Baecke S, Kenning P (2008). What they see is what they get? An fMRI-study on neural correlates of attractive packaging. J. Consum. Behav., 7: 342-359 
[39] Wilson, R., Gaines, J. and Hill, R. (2008). NM and consumer free will. Journal of consumer affairs, 42(3), pp.389-410.

[40] Wilson, T. (2002). Strangers to ourselves. 1st ed. Cambridge, Mass.: Belknap Press of Harvard University Press.

[41] Wulfemeyer, K.T. and Mueller, B., 1992. Channel One and commercials in classrooms: Advertising content aimed at students. Journalism Quarterly, 69(3), pp.724-742.

[42] Yoon, C., Gutchess, A.H., Feinberg, F. and Polk, T.A. (2006), “A functional magnetic resonance imaging study of neural dissociations between brand and person judgments", Journal of Consumer Behavior, Vol. 33, pp. 31-40.

[43] York:: Lexington Books

[44] Zak PJ (2004). Neuroeconomics. Philosophical Transactions of the Royal Society B, 359: 1737-1748. 